\title{
Small signal stability analysis of power systems with high penetration of wind power
}

\author{
Ping HE, Fushuan WEN ( $₫)$, Gerard LEDWICH, \\ Yusheng XUE
}

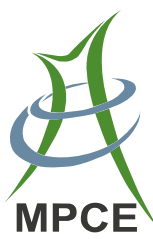

\begin{abstract}
The integration of large amount of wind power into a power system imposes a new challenge for the secure and economic operation of the system. It is necessary to investigate the impacts of wind power generation on the dynamic behavior of the power system concerned. This paper investigates the impacts of large amount of wind power on small signal stability and the corresponding control strategies to mitigate the negative effects. The concepts of different types of wind turbine generators (WTGs) and the principles of the grid-connected structures of wind power generation systems are first briefly introduced. Then, the state-of-the-art of the studies on the impacts of WTGs on small signal stability as well as potential problems to be studied are clarified. Finally, the control strategies on WTGs to enhance power system damping characteristics are presented.
\end{abstract}

Keywords Wind turbine generators, Wind farm integration, Small signal stability, Damping characteristic

Received: 1 July 2013/ Accepted: 7 August 2013/Published online: 9 October 2013

(c) The Author(s) 2013. This article is published with open access at Springerlink.com

P. HE, South China University of Technology,

Guangzhou 510640, China

e-mail: hplkz@126.com

P. HE, Zhengzhou University of Light Industry,

Zhengzhou 450002, China

F. WEN, G. LEDWICH, Queensland University of Technology,

Gardens Point, Brisbane, Australia

$(\triangle)$ e-mail: fushuan.wen@gmail.com

G. LEDWICH

e-mail: g.ledwich@qut.edu.au

Y. XUE, State Grid Electric Power Research Institute,

Nanjing 210003, China

e-mail: xueyusheng@sgepri.sgcc.com.cn

\section{Introduction}

The energy policies in many industrialized countries place the emphasis on the large-scale development of renewable energy-based power generation. The everincreasing power generation from renewable energy sources, especially wind energy, would be helpful for reducing the emissions of pollutions, and hence mitigate global warming and improve environment. The wind power reserve is huge around the globe. It is reported in [1] that the technical potential of onshore wind energy is very large, around $2.74 \times 10^{12}-5.0 \times 10^{12} \mathrm{KWh}$ (kilowattshour). It is estimated by the Global Wind Energy Council that about $2 \times 10^{7} \mathrm{MW}$ of electricity could be utilized, which is ten times larger than the available water energy. In the past decades, more and more wind power is integrated to power systems around the globe, and the trend is expected to continue in the foreseeable future [2].

The wind energy reserve in China is abundant, the onshore wind potential reaches $3.226 \times 10^{7} \mathrm{KWh}$ per year, in which about $2.53 \times 10^{6} \mathrm{KWh}$ can be utilized; while the offshore wind energy potential reaches $7.5 \times 10^{6} \mathrm{KWh}$ [2] According to global wind report 2011 [3] from European Wind Energy Association (EWEA), around $2 \times 10^{4} \mathrm{MW}$ [3] of new wind energy capacity were installed in China in 2011, and the total wind installed capacity reached about $6.5 \times 10^{4}$ MW by the end of 2011 .

In recent years, the installation of wind power energy has moved from small wind farms with a few wind turbines to large wind farms with more than hundreds of MW of capacity, and the connection point of wind farm have developed from low-voltage-level electricity distribution system to high-voltage-level electricity transmission system. With the increasing penetration level, the impact of wind power on power system dynamics and stability become increasingly complicated. The increasing utilization of wind 
power gives rise to a new set of problems [4] in frequency fluctuations, harmonics pollution as well as concerning the safe and stable operation, the peaking and frequency modulation and the economical dispatch of power systems. Consequently, the impact of wind power penetration on power system stability [5-20] has drawn great attention to the power system engineers and scientists. Meanwhile, the large-scale interconnected power system is forming in China, and the problem of the weak damp or negative damp status between inter-network or local network with wind power integrated to power systems is critical. Besides, the increasing capacity and different connection point of wind power maybe worsen the damping performances of power systems, meanwhile, wind power resources are generally located far from large centers of consumption, which may involve transmitting energy for long distances through congested lines and perhaps a significant change of generation profile and typical power flows, and may have significant impact on small signal stability. Therefore, it's necessary to systematically analyse the influence of wind power integration on power system oscillation mode and damping characteristic.

The purpose of this paper is to analyze the impacts of wind power on small signal stability and corresponding control strategies to improve power system damping characteristic and get a summarized study on the hot topics. The paper is organized as follows: Section 2 introduces the characteristics of WTGs including the different types and technologies of wind power grid connected. The principles and methods of power system small signal stability analysis are described in Section 3. Section 4 summarizes the effects of large scale wind power on small signal stability, including the analysis of the modeling and simulation, the research on power system oscillation mode and damping characteristic, and the auxiliary control strategies on WTGs to reinforce small signal stability. The conclusion is given in Section 5.

\section{Characteristics of WTGs}

WTGs are used to extract the kinetic energy from the wind and then convert it into electricity. Wind turbines usually rotate at a speed of 3-30 miles/h. WTGs system normally consists of wind turbine, generator, grid interface converters, wind blades, yaw control, brake, gear box, control device, and an anemometer, etc.

For the moment, there are three prevailing kinds of WTGs in the market, including the squirrel cage induction wind power generator (SCIG), the doubly-fed induction wind power generators (DFIG), and the direct-driven permanent magnet wind power generators (DDPMG). In this section, the characteristic of three popular types $[1,2]$ of

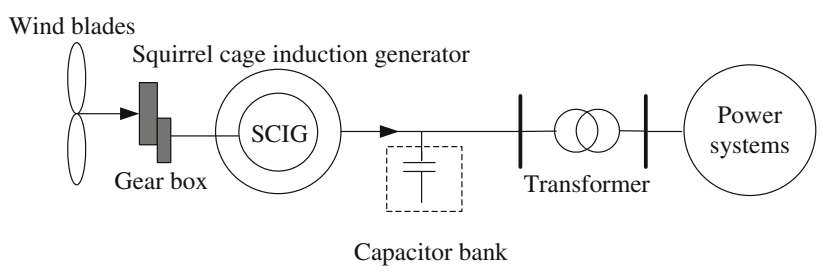

Fig. 1 Schematic diagram of SCIG system

WTGs and the technologies [8-12] of wind power grid connected are introduced briefly.

\subsection{SCIG}

The wind turbine rotor is connected to the generator through a gear box and the stator is directly coupled to the grid as shown in Fig. 1. SCIG always has high reactive power consumption and hence uses capacitor banks to maintain the required voltage level at the grid. The slip, and hence the rotor speed of a SCIG varies with the amount of power generated. These rotor speed variations are very small, approximately 1 to 2 percent. Therefore, this wind turbine type is normally referred to as a constant speed or fixed speed turbine. Nonetheless, they can run at two different speeds by changing the number of pole pairs of the stator windings.

\subsection{DFIG}

The schematic diagram of a grid-connected DFIG system is depicted in Fig. 2. The DFIG system includes the wind turbine, the drive train, the gear box, the induction generator and the back-to-back pulse width modulation (PWM) converters. The stator is directly coupled to the grid and the rotor is connected to the gird through the PWM converters. The active power and reactive power of DFIG can be decoupled control by adjusting the rotor side converter modulation coefficient, which can improve the energy conversion efficiency, enhance the power factor of wind farms and the voltage stability. This makes DFIG popular in the recent years $[1,9,10]$. However, because the internal resistance of DFIG is very small, the capacity of DFIG damped oscillation is limited.

\subsection{DDPMG}

The DDPMG wind power system involves the wind turbine generator, the drive train and the full scale back-to-back PWM converters, as presented in Fig. 3. The rotor of DDPMG is directly connected to the generator and the stator is coupled to the grid through a full-scale PWM converter. By comparing to DFIG, DDPMG saves the gear box, the 


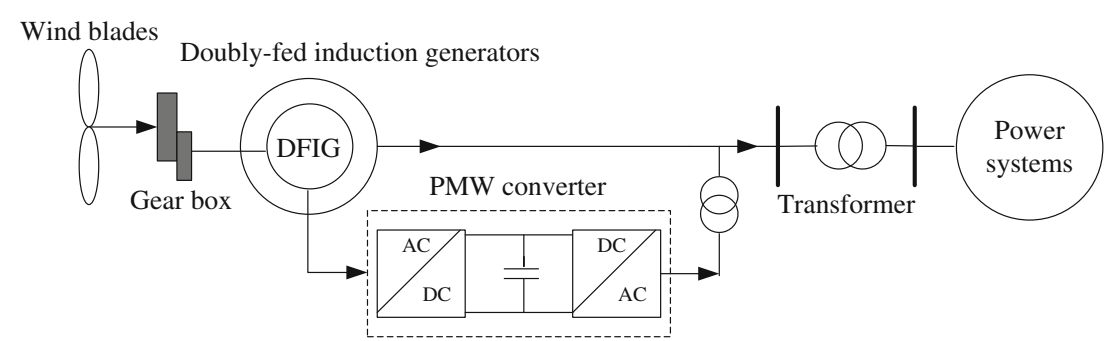

Fig. 2 Schematic diagram of DFIG system

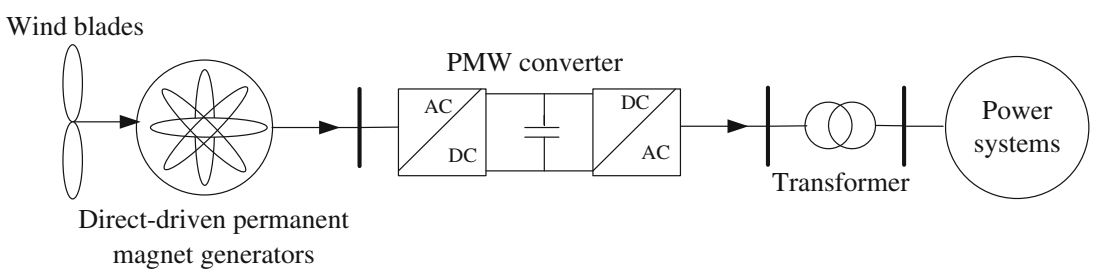

Fig. 3 Schematic diagram of DDPMG system

brush and the slip ring, which improves the operation reliability, reduces the maintenance cost, however, it needs fullscale converter. The output electromagnetic power of DDPMG is controlled by the pitch angle control and the fullscale PWM converter, which makes DDPMG and the electrical grid completely decoupled.

\subsection{Performance comparisons}

Each of these WTGs has its own advantages and disadvantages as elaborated in $[1,5,8,12]$. They can be summarized [8] using Table 1. The main strength of DFIG is that more energy can be generated for a specific wind range, and the more efficient aerodynamic, besides, there is a reduced mechanical stress as the rotor acts as a flywheel thereby reducing the drive train torque variations. The major drawbacks of DDPMG are that they are large, heavy and complex ring generators and need large power electronic converter.

Table 1 Comparison of different WTGs

\begin{tabular}{|c|c|c|}
\hline & Advantages & Disadvantages \\
\hline SCIG & $\begin{array}{l}\text { Less expensive, electrically } \\
\text { efficient simple and } \\
\text { robust construction }\end{array}$ & $\begin{array}{l}\text { Noisy, high mechanical } \\
\text { stress, aerodynamically } \\
\text { less efficient, requires } \\
\text { gear box }\end{array}$ \\
\hline DFIG & $\begin{array}{l}\text { Less noisy, } \\
\text { aerodynamically efficient } \\
\text { small rating converter }\end{array}$ & $\begin{array}{l}\text { It is expensive and } \\
\text { electrically less efficient, } \\
\text { requires gear box }\end{array}$ \\
\hline DDPMG & $\begin{array}{l}\text { Less noisy, } \\
\text { aerodynamically efficient, } \\
\text { no gear box, less } \\
\text { mechanical stress }\end{array}$ & $\begin{array}{l}\text { Needs large rating } \\
\text { converter, expensive, } \\
\text { heavy and large generator }\end{array}$ \\
\hline
\end{tabular}

\section{Power system small signal stability}

Small signal stability (or small-disturbance stability) in a power system is the ability of the system to ascertain a stable operating condition following a small perturbation around its operating equilibrium [7, 21]. Of particular importance in the analysis of small-signal stability is the determination of the electromechanical modes of oscillation (EMO). The electromechanical modes involve the rotors of individual generators or of groups of generators oscillating or swinging against each other, and they can be subdivided into inter-area, local-area and intra-station modes [7].

Small signal stability analysis is carried out based on the system nonlinear equations, describing the dynamic behavior of the system, linearized around a chosen operating point. Based on the motion of the rotors and the torque characteristics of generator, the mechanism of small signal stability is analyzed, such as the negative damping mechanism, the resonance mechanism, nonlinear singular and chaos mechanism [22-24].

It has been known that there are two factors in influencing the small signal stability of power systems.

1) Lack of sufficient synchronizing torque, which is proportional to the power angle increment, resulting in an increasing of the rotor angle of the generator.

2) Lack of sufficient damping torque, which is proportional to the generator rotational speed increment, resulting in an increasing oscillation of the rotor.

At present, there are two main methods for analyzing power system small signal stability. 
1) Eigenvalue analysis method based on the state space model;

2) Frequency domain analysis method based on the transfer function matrix.

Eigenvalue analysis method, which based on the linear system theory and Lyapunov stability theory, has been recognized as one of the broadest methods to analyze small signal stability. In this method, the complex power system can be linearized around a stable operating point which can give a close approximation to the system to be studied [7]. And then, stability analysis is done by computing eigenvalues as well as the right and left eigenvectors of its state matrix, hence the judgment information of system stability, such as the oscillation frequency, the attenuation factor, the impact factor, and the strongly correlated state variables, can be obtained. At present, eigenvalue analysis method is a powerful tool to research the electromechanical mode and the damping performances of power systems, and it has been successfully used in small signal stability evaluation, the damping controller siting determination [25] and parameter optimization [26, 27] and so on.

The frequency domain model of power systems described by the transfer function matrix, i.e. $\boldsymbol{y}(s)=\boldsymbol{G}(s) \boldsymbol{u}(s)$, (where, $\boldsymbol{y}(s)$ is the output vector; $\boldsymbol{G}(s)$ is the transfer function matrix; $\boldsymbol{u}(s)$ is the input vector), can be obtained by appropriately choosing the input and output variables. The system is stable under small disturbance, which is equivalent in the negative real part of all poles of $\boldsymbol{G}(s)$, and it can be examined by the multivariable Nyquist stability criteria. The scale of power system had little impact on the frequency domain analysis method, which makes it reliable to analyze the large scale power systems. Whereas compared eigenvalue analysis method, it provides insufficient information. However, with the development of modern multivariable control system frequency domain theory, frequency domain analysis method gets more and more attentions by the electricity workers in recent years, and then achieves further development. The frequency domain analysis model of power system small signal stability, including the high-voltage direct current (HVDC), is built in [28]. And in [29], it is applied to the robust stability analysis of power systems.

The well-known power system stabilizer (PSS) [21, 25, $26]$ is used to generate supplementary control signals for the excitation system of a generator so as to damp low frequency oscillations in the power system concerned. Intelligent algorithm is introduced to the PSS design [27] in recent years, and some simple structure, adaptable, and better robustness PSS are used to control the large scale power system stability.

\section{Impacts of wind power integration on small signal stability}

\subsection{Modeling and simulation}

The increasing wind power penetration on power systems requires the development of adequate wind farm models for representing the dynamic behavior of wind farms on power systems. A lot of researching and analyzing works [10, 13-15, 30-33] by the scholars have been done on modeling and simulation for power system small signal stability with wind power integration, which include modeling of three popular WTGs and the power system small signal analysis with penetration of wind power, and the focus of research is DFIG.

A reduced order dynamic modeling of large (MW) capacity fixed speed and doubly-fed asynchronous generator wind turbine is discussed in [10], in the model, speed control characteristics and converter protection of the DFIG are implemented. Meanwhile, a dynamic model is also derived in [13], which can be used to simulate the DFIG wind turbine using a single-cage and double-cage representation of the generator rotor, as well as a representation of its control and protection circuits. This model can also be used to investigate transient stability of large power systems.

Reference [14] gives the modeling of the DFIG considering operating conditions below and above synchronous speed, which are actually achieved by means of a double-sided PWM converter joining the machine rotor to the grid. And the stator-flux-oriented vector control is applied to decouple the active and reactive powers generated by the generator. Likewise, the steady-state analysis of DFIG in the subsynchronous and supersynchronous regions is also discussed in [15]. An optimum control strategy, which maximizes the total electrical power output of the double output induction generator is determined, and a equivalent circuit is given, but in which core losses and harmonics are ignored.

Based on the relationship of flux linkage, potential and electric current, dynamic mathematics model of DFIG is deduced in [30], and this model neglects the stator transients and the harmonics of electrical magnitudes. The development of equivalent wind farm models can reduce the model order and the computation time under the impact of wind farms on power systems. Two equivalent wind turbines are developed in [31] by using MATLAB/Simulink: one for aggregated wind turbines with similar winds, and another for aggregated wind turbines under any incoming wind. A wind park dynamic model together with a base methodology for its application to power system studies is presented in [32], which is applied to the 
operating conditions of the selected sets of wind turbine experimental benchmark data from actual wind parks, and the results show its effectiveness. And a unified, modular, small-signal dynamic model of DFIG is presented in the PSCAD/EMTDC environment [33]. Similarly, a SCIG simulation model with thyristor-based soft-start module is presented in [20].

From the present literatures, it can be seen that the modeling techniques of WTGs based on aerodynamic have been relatively mature. Many simulation softwares, such as DIgSILEN/Power Factory, PSASP, MATLAB, PSS/E, PSCAD/EMTDC, include the WTG module. In the actual research, the detailed or simplified model can be built according to the aim of the research to study the small signal stability of power systems with wind power integration.

\subsection{Influence of wind power integration on power system oscillation mode and damping characteristics}

With the increase in penetration of these wind turbines, the power system dominated by synchronous machines will experience a change in dynamics and operational characteristics. Given this assertion, Slootweg and Klind initiated the issue that the impact of constant speed WTGs and variable speed WTGs on small signal stability of power systems in 2003 [11]. Later on more researchers started to concentrate on this subject by the means of modal analysis or time-domain simulations, and then the impact of large scale wind power integration on power system oscillation modes and damping performances has become a hot research topic.

The impact of DFIG based wind farms on the system small signal stability is investigated in [12], which showed that the DFIG based wind generating system has negative damping under changed operating condition (wind speed), thus this paper suggest the additional damping controller should be adopted.

The impact of increasing wind power on the damping performance of the New Zealand power system is assessed in [16]. The damping performance of different scenarios is compared, based on the eigenvalues of a linearized model; the studies indicate that the damping performance of the system is not materially affected by the types of wind energy converter technology (SCIG, DFIG, or DDPMG). Moreover, [17] investigates the impact of wind power integration in Norway on the damping of interarea mode oscillations in the Nordic grid. The impact on the interarea mode oscillations is tested for various types of generators. The results show that SCIG improves the damping of the interarea mode oscillation between Norway and Sweden, while DFIG and DDPMG decrease the damping.
Table 2 Different impacts of WTGs on dampings

\begin{tabular}{lcc}
\hline & Positive & Negative \\
\hline SCIG & $\boldsymbol{v}$ & \\
DFIG & $\boldsymbol{v}$ & $\boldsymbol{\checkmark}$ \\
DDPMG & $\boldsymbol{v}$ & $\boldsymbol{V}$ \\
\hline
\end{tabular}

According to the linearization-based eigenvalue analysis, time domain simulations, and probabilistic eigenvalue analysis, [18] shows that large wind power integration can have positive or negative impacts on system damping depending on the location of the wind power plant, the amount of the conventional generation replaced by wind power and the stress level of the power system.

The effect of increased penetration of DFIG on the stability of inter-area oscillations in a small typical power system is examined by the PSS/E program in [19]. It is shown that the effect is generally favorable, but sometimes the inter-area mode is less damped or can even be destabilized.

Power system oscillation damping with DFIG is investigated in $[34,35]$, and the transient and small signal stability of DFIG are analyzed in [36] by using the sensitivity of the eigenvalues with respect to inertia. Both beneficial and detrimental impacts with the increased penetration of DFIG are found. Meanwhile, [37] advocates that DDPMG without the controllers will have no adverse effect on the stability.

It is widely agreed that SCIGs, whose stators are directly coupled to the grid, have positive impacts on system damping, as shown in Table 2; DFIGs and DDPMG have both positive and negative impacts on the damping performance of the electromechanical oscillation modes. In practice, the effect of WTGs on power system small signal stability should be discussed according to the types of oscillations, the capacity of integrated wind power and different connection points.

\subsection{Control strategies on WTGs to improve power} system damping characteristic

According to the analysis above, WTGs require additional controllers to damp power system oscillations. In this section, control strategies on WTGs to improve power system damping characteristic are reviewed.

During the last few decades, many different maximum power point tracking (MPPT) control strategies have been developed in [38] and [39]. This enabled the selection of the optimal MPPT for each wind energy conversion system (WECS) project. And a prototype version of the control strategy of a $20 \mathrm{KW}$ DDPMG for maximum power tracking is proposed in [40] for the WECS. 
The auxiliary control loop for oscillation damping that adjusts the active power command to damp the interarea oscillation is proposed in [35]. Moreover, a power system stabilizer (PSS) using a speed deviation is proposed in [41]. It is reported that the presence of the PSS in the DFIG system improves the damping of the oscillations in the network. Nevertheless, it is very important to optimize the controller parameters of the PSS to achieve the best performance.

Reference [42] focuses on the impact of a damping controller on the super/subsynchronous operation of DFIG, which would help in proper tuning of the DFIG controllers to enhance the system small-signal stability. Based on the concept of dynamic frequency character, the phase and amplitude conditions for wind farms to produce the positive damping effects on their connected power systems are proved in [43], and a damping control strategy of DFIG is studied on 2-area and multi-area power systems by means of Power System Analysis Software Package (PSASP). Meanwhile, a control strategy for the multilevel frequency converter of DDPMG is proposed to augment the low voltage ride through (LVRT) requirement as well as to minimize voltage fluctuation in [44].

Recently, a flux magnitude and angle controller (FMAC) scheme is put forward for DFIGs, by which the terminal voltage and stator power can be controlled via the magnitude and angle of the rotor flux vector decouply [45]. For DFIG, eigenvalue sensitivity [46] is used to design damping controllers aimed at damping electromechanical oscillations. Additionally, multi-objective optimal controller design using differential evolution (DE) of DFIG is presented in [47]. Eigenvalue analysis and time-domain simulations are performed on a single machine infinite bus system as well as a nine-bus multi-machine system to illustrate the control performance of DFIG with the optimised controller parameters. Particle swarm optimisation (PSO) [48] is also applied for optimising parameters of controllers of DFIG.

\section{Conclusions}

The influence of large scale wind power integration on power system small signal stability and the corresponding control strategies are analyzed in this paper as follows.

1) Nowadays, there are three major types of WTGs on the market: SCIG, DFIG, and DDPMG. It is universally accepted that SCIGs have a positive effect on the damping characteristic while the pros and cons impacts of DFIG and DDPMG are presented. In fact, the factors, such as the types of WTGs, the way of grid-connected, the capacity of integrated wind power and the different connection point, will bring different effect on the system damping, which maybe beneficial or detrimental.

2) The topic research of power system small signal stability with wind power penetration focuses on the modal analysis and time-domain simulations, through which the impact of wind power on power system oscillation modes and damping performances are discussed.

3) It is found that the current hot focuses of the research of improving power system damping characteristic with wind power integration are mostly in the control strategies of the additional damping controller, including the controller design, optimization of the parameter of the damping controller, the coordinated tuning of different controllers, eigenvalue sensitivities, the input signal selection, PSS, and so on.

4) The simulation softwares used in researching wind power grid-connected systems mostly include DIgSILEN/Power Factory, PSASP, MATLAB, PSS/E, and PSCAD/EMTDC, which provide the user with a convenient WTG module for further study.

Acknowledgments This work is supported by a discovery project of Australia Research Council (No. DP120101345), and National Key Technology Research and Development Program of China (No. 2011BAA07B02).

Open Access This article is distributed under the terms of the Creative Commons Attribution License which permits any use, distribution, and reproduction in any medium, provided the original author(s) and the source are credited.

\section{References}

[1] Joselin Herbert GM, Iniyan S, Sreevalsan E et al (2007) A review of wind energy technologies. Renew Syst Energy Rev 11(6):1117-1145

[2] Ackermann T (2005) Wind power in power systems. Wiley, Chichester

[3] Annual market update (2011) Global wind Report. Global Wind Energy Council (GWEC), Brussels, Belgium

[4] Sorensen P, Cutululis NA, Vigueras-Rodriguez A (2007) Power fluctuations from large wind farms. IEEE Trans Power Syst 22(3):958-965

[5] Sun YZ, Wang LX, Li GJ et al (2010) A review on analysis and control of small signal stability of power systems with large scale integration of wind power. In: Proceedings of the 2010 international conference on power system technology (POWERCON'10), Hangzhou, 24-28 Oct 2010, p 6

[6] Saifur R, Pipattanasomporn M (2011) Operating impacts and mitigation strategies with large-scale wind power penetration in 
the United States. Automat Electr Power Syst 35(22):3-11 (in Chinese)

[7] Kundur P (1994) Power system stability and control. McGrawHill, New York

[8] Chedid R, LaWhite N, Ilic M (1993) A comparative analysis of dynamic models for performance calculation of grid-connected wind turbine generators. Wind Energy 17(4):168-182

[9] Yang LH, Xu Z, Ostergaard J et al (2012) Advanced control strategy of DFIG wind turbines for power system fault ride through. IEEE Trans Power Syst 27(2):713-722

[10] Holdsworth L, Wu XG, Ekanayake JB et al (2003) Comparison of fixed speed and doubly-fed induction wind turbines during power system disturbances. IEE P-Gener Transm Distrib 150(3):343-352

[11] Slootweg JG, Klind WL (2003) The impact of large scale wind power generation on power system oscillations. Electr Power Syst Res 67(1):9-20

[12] Yateendra M (2008) Advances in power system small signal stability analysis considering load modeling and emerging generation resources. Dissertation, The University of Queensland, Brisbane

[13] Ekanayake JB, Holdsworth L, Wu XG et al (2003) Dynamic modeling of doubly fed induction generator wind turbines. IEEE Trans Power Syst 18(2):803-809

[14] Tapia A, Tapia G, Ostolaza JX et al (2003) Modeling and control of a wind turbine design doubly fed induction generator. IEEE Trans Energy Convers 18(2):194-204

[15] Cadirci I, Ermis M (1992) Double-output induction generator operating at subsynchronous and supersynchronous speeds: steady-state performance optimisation and wind-energy recovery. IEE P-Electr Power Appl 139(5):429-442

[16] Vowles DJ, Samarasinghe C, Gibbard MJ et al (2008) Effect of wind generation on small-signal stability-A New Zealand example. In: Proceedings of the 2008 IEEE power and energy society general meeting - conversion and delivery of electrical energy in the 21st century, Pittsburgh, 20-24 Jul 2008, p 8

[17] Hagstrøm E, Norheim I, Uhle K (2005) Large scale wind power integration in Norway and effect on damping in the Nordic grid. Wind Energy 8(3):375-384

[18] Rueda JL, Erlich I (2011) Impacts of large scale integration of wind power on power system small-signal stability. In: Proceedings of the 4th international conference on electric utility deregulation and restructuring and power technologies (DRPT'11), Weihai, 6-9 Jul 2011, pp 673-681

[19] Tsourakisa G, Nomikosb BM, Vournas CD (2009) Effect of wind parks with doubly fed asynchronous generators on smallsignal stability. Electr Power Syst Res 79(1):190-200

[20] Quinonez-Varela G, Cruden A (2008) Modelling and validation of a squirrel cage induction generator wind turbine during connection to the local grid. IET Gener Transm Distrib 2(2):301-309

[21] Kundur P, Paserba J, Ajjarapu V et al (2004) Definition and classification of power system stability IEEE/CIGRE joint task force on stability terms and definitions. IEEE Trans Power Syst 19(3):1387-1401

[22] Demello FP, Concordia C (1969) Concepts of synchronous machine stability as affected by excitation control. IEEE Trans Power Appl Syst 88(4):316-329

[23] Gomes S, Martins N, Portela C (2003) Computing small signal stability boundaries for large-scale power systems. IEEE Trans Power Syst 18(2):747-752

[24] Srivastava KN, Srivastava SC (1998) Elimination of dynamic bifurcation and chaos in power systems using FACTS devices. IEEE Trans Circ Syst I 45(1):72-78

[25] Tse CT, Tso SK (1988) Design optimization of power system stabilizers based on modal and eigen sensitivity analyses. IEE P-Gener Transm Distrib 135(5):406-415
[26] Wang KW, Chung CY, Tse CT et al (2000) Multimachine eigenvalue sensitivities of power system parameters. IEEE Trans Power Syst 15(2):741-747

[27] He P, Wang KW, Tse CT et al (2007) Studies of the improvement of probabilistic PSSs by using the single neuron model. Int J Electr Power Energy Syst 29(3):217-221

[28] Osauskas CM, Hume DJ, Wood AR (2001) Small signal frequency domain model of an HVDC converter. IEE P-Gener Transm Distrib 148(6):573-578

[29] Anderson PM, Fouad AA (2002) Power system control and stability. Wiley, Chichester

[30] Feijóo A, Cidrás J, Carrillo C (2000) A third model for the doubly-fed induction machine. Electr Power Syst Res 56(2):121-127

[31] Fernández LM, Saenz JR, Jurado F (2006) Dynamic models of wind farms with fixed speed wind turbines. Renew Energy 31(8):1203-1230

[32] Estanqueiro AI (2007) A dynamic wind generation model for power systems studies. IEEE Trans Power Syst 22(3):920-928

[33] Tabesh A, Iravani R (2008) Small-signal model and dynamic analysis of variable speed induction machine wind farms. IET Renew Power Gener 2(4):215-227

[34] Tsourakis G, Nomikos BM, Vournas CD (2009) Contribution of doubly fed wind generators to oscillation damping. IEEE Trans Energy Convers 24(3):783-791

[35] Fan LL, Miao ZX, Osborn D (2008) Impact of doubly fed wind turbine generation on inter-area oscillation damping. In: Proceedings of the 2008 IEEE power and energy society general meeting-Conversion and delivery of electrical energy in the 21st century, Pittsburgh, 20-24 Jul 2008

[36] Gautam D, Vittal V, Harbour T (2009) Impact of increased penetration of DFIG-based wind turbine generators on transient and small signal stability of power systems. IEEE Trans Power Syst 24(3):1426-1434

[37] Wu F, Zhang XP (2009) Small signal stability analysis and control of the wind turbine with the direct-drive permanent magnet generator integrated to the grid. Electr Power Syst Res 79(12):1661-1667

[38] Chedid R, Mrad F, Basma M (1999) Intelligent control of class of wind energy conversion systems. IEEE Trans Energy Convers 14(4):1597-1604

[39] Mohamed AZ, Eskander MN, Ghali FA (2001) Fuzzy logic control based maximum power tracking of wind energy system. Renew Energy 23(2):235-245

[40] Tan K, Islam S (2004) Optimum control strategies in energy conversion of PMSG wind turbine system without mechanical sensor. IEEE Trans Energy Convers 19(2):392-399

[41] Hughes FM, Anaya-Lara O, Jenkins N et al (2006) A power system stabilizer for DFIG-based wind generation. IEEE Trans Power Syst 21(2):763-772

[42] Mishra Y, Mishra S, Li FX et al (2009) Small-signal stability analysis of a DFIG-based wind power system under different modes of operation. IEEE Trans Energy Convers 24(4):972-982

[43] Hao Z, Yu Y, Zeng Y (2011) Control strategy for increasing power system damping with wind turbine-driven doubly-fed induction generator. Autom Electr Power Syst 35(15):25-29 (in Chinese)

[44] Muyeen SM, Takahashi R, Murata T et al (2010) A variable speed wind turbine control strategy to meet wind farm grid code requirements. IEEE Trans Power Syst 25(1):331-340

[45] Anaya-Lara O, Hughes FM, Jenkins N et al (2006) Rotor flux magnitude and angle control strategy for doubly fed induction generators. Wind Energy 9(5):479-495

[46] Sigrist L, Rouco L (2009) Design of damping controllers for doubly fed induction generators using eigenvalue sensitivities. In: Proceedings of the power systems conference and exposition (PSCE'09), Seattle, 15-18 Mar 2009, p 7 
[47] Yang L, Yang GY, Xu Z et al (2010) Optimal controller design of a doubly-fed induction generator wind turbine system for small signal stability enhancement. IEE P-Gener Transm Distrib 4(5):579-597

[48] Wu F, Zhang XP, Godfrey K et al (2007) Small signal stability analysis and optimal control of a wind turbine with doubly fed induction generator. IEE P-Gener Transm Distrib 1(5):751-760

\section{Author Biographies}

Ping HE received her B.E. and M.E. degrees from Zhengzhou University, China, in 2003 and 2006, respectively. She has been a lecturer at Zhengzhou University of Light Industry since 2006. She is concurrently pursuing the Ph.D. degree in South China University of Technology. Her research interests include power system stability analysis and control, wind power generation.

Fushuan WEN received his B.E. and M.E. degrees from Tianjin University, China, in 1985 and 1988, respectively, and Ph.D. from Zhejiang University, China, in 1991, all in electrical engineering. He joined the faculty of Zhejiang University in 1991, and has been a full professor and the director of the Institute of Power Economics and Information since 1997, and the director of Zhejiang
University-Insigma Joint Research Center for Smart Grids since 2010. He had been a university distinguished professor, the deputy dean of the School of Electrical Engineering and the director of the Institute of Power Economics and Electricity Markets in South China University of Technology (SCUT), China, from 2005 to 2009. His current research interests include power industry restructuring, power system alarm processing, fault diagnosis and restoration strategies, and smart grids.

Gerard LEDWICH received his Ph.D. degree in electrical engineering from the University of Newcastle, Newcastle, Australia, in 1976. He has been a Chair Professor in electrical asset management at Queensland University of Technology (QUT), Brisbane, Australia, since 1998. His interests are in the areas of power systems, power electronics, and controls. Prof. Ledwich is a Fellow of I.E. Australia and a senior member of IEEE.

Yusheng XUE received his Ph.D. degree in Electrical Engineering from the University of Liege (Belgium) in 1987. He became a Member of Chinese Academy of Engineering in 1995. He is now the Honorary President of State Grid Electric Power Research Institute (SGEPRI), State Grid Corporation of China. His research interests include nonlinear stability, control and power system automation. 